\title{
KARAKTERISTIK SORPSI DAN DESORPSI FOSFAT PADA OXISOL DENGAN PENDEKATAN KINETIK
}

\author{
Mimien Haryanti \\ Jurusan Tanah Fakultas Pertanian Universitas Andalas
}

\begin{abstract}
The phosphorous sorption and desorption characteristics were studied in Oxisols Padang Siantah West Sumatera. The amount of P $(0,20,40,80,100,200,400,800 \mu \mathrm{g}$ P) was added to 1 gram soil and incubated for 0.04 days ( 1 hour) , 0.125 days ( $3 \mathrm{~h}), 0.25$ days $(6 \mathrm{~h}), 0.375$ days (9 h), 1,3, 6, 9, 18 dan 36 days. A completely factorial design in triple replication was set up. The results of $\mathrm{P}$ sorption and desorption experiment showed that Oxisol had very high sorption with time until 99 from added P. P desorption maximum at the time was 3 days with sorption value $1,67 \%$ from added $P$.
\end{abstract}

Keywords : Oxisol, Fe and Al oksides, $P$ sorption, $P$ desorption, time of reaction.

\section{PENDAHULUAN}

Tanaman dapat langsung mengambil ion P dari larutan tanah, hal ini merupakan tujuan dilakukannya pemupukan $\mathrm{P}$ pada tanah. Pupuk P ketika diberikan ke dalam tanah akan berpeluang terjerap oleh permukaan mineral dan diendapkan oleh mineral $\mathrm{P}$ sekunder. Ion $\mathrm{P}$ akan diendapkan sebagai mineral sekunder Fe-P dan Al-P atau dijerap pada permukaan senyawa oksida Fe dan Al atau oleh mineral liat (Havlin et al, 1999).

Oxisol adalah tanah tropis yang telah mengalami pelapukan lanjut, sehingga komponen tanah ini lebih didominasi oleh oksida dan hidro-oksida Al dan Fe. Muatan positif dari koloid lebih besar pada Oxisol. Penggantian ion $\mathrm{OH}$ dari hidrous $\mathrm{Fe}$ dan oksida $\mathrm{Al}$ adalah mekanisme penting dalam pertukaran anion. Pada kondisi tanah masam dengan $\mathrm{pH}$ rendah yaitu sekitar 4-5, muatan positif berperan dalam adsorpsi dan pertukaran anion pada patahan mineral, terutama dalam lapis Al Oktahedral yaitu dengan munculnya ekspos grup $\mathrm{OH}$ pada patahan kaolinit. Pada kebanyakan tanah, $\mathrm{H}_{2} \mathrm{PO}_{4}^{-}$adalah anion yang paling banyak dijerap, dan dapat ditahan partikel tanah melalui reaksi adsorpsi (Brady dan Weil, 1999).

Sorpsi $\mathrm{P}$ pada tanah-tanah masam terutama terjadi pada permukaan oksida dan hidroksida Fe dan Al. Sorpsi $\mathrm{P}$ terjadi melalui pertukaran ligand pada muatan variabel permukaan dengan pertukaran $\mathrm{OH}$ dengan ion $\mathrm{P}$ pada permukaan. Ikatan kovalen terdapat antara ion logam dan ion fospat. Ion P dijerap terutama pada komplek bagian dalam matrik yang berarti bahwa sorpsi menempati sisi koordinasi spesifik pada oksida atau hidroksida dan tidak ada molekul air yang berada antara permukaan dan ion fospat (Borling, 2003).

Pemupukan $\mathrm{P}$ bagi tanaman pada Oxisol yang didominasi oleh oksida dan hidroksida Fe dan Al tidak akan menjadi efektif karena pupuk $\mathrm{P}$ akan segera dijerap oleh matrik tanah yang dipenuhi oksidahidroksida Fe dan Al yang mempunyai luas permukaan yang besar. Sorpsi P dipengaruhi oleh jenis mineral liat, dimana Oxisol didominasi oleh mineral liat yang telah melapuk lanjut seperti oksida-oksida Fe, Al (hematit, gibsit dan goetit) dengan muatan yang bervariasi (Brady dan Weil, 1999). Berdasarkan hasil penelitian Fiantis (1989) pemupukan pada tanah Oxisol Padang Siantah sampai dengan $150 \mathrm{Kg}_{2} \mathrm{O}_{5} / \mathrm{Ha}$ belum mempengaruhi pertumbuhan dan produksi kedelai, karena tingginya kapasitas sorpsi $\mathrm{P}$ pada tanah ini, sehingga pupuk $\mathrm{P}$ yang diberikan lebih cepat terjerap pada matrik tanah, sebelum tanaman menyerap $\mathrm{P}$ dari pupuk yang diberikan.

Pada penelitian Nuryanti (2003), ditemukan bahwa $\mathrm{P}$ yang harus ditambahkan untuk mencapai 0,2 ppm (yaitu konsentrasi $\mathrm{P}$ dalam larutan tanah untuk mendukung pertumbuhan yang optimum bagi tanaman (Brady dan Weil, 1999), pada Oxisol Padang Siantah yaitu 2.978 Ton/Ha pada lapisan permukaan Oxisol dan 2.982 Ton/Ha pada lapisan permukaan bawah. Dalam hal ini 
pupuk P dibutuhkan dalam jumlah yang relatif banyak untuk memenuhi ketersediaan $\mathrm{P}$ bagi tanaman pada Oxisol. Pemupukan yang berat pada Oxisol menjadi masalah utama dalam mengelola tanah ini untuk produksi pertanian.

Menurut Buehler, Oberson, Rao, Fiersen, Frossard (2002), pada lahan yang dipupuk dengan $\mathrm{P}$ sekali atau tidak dipupuk sama sekali pada Oxisol, maka P sedikit sekali yang dapat dipertukarkan. Sejumlah $\mathrm{P}$ dapat dilepaskan ke larutan tanah dari permukaan yang mempunyai muatan variabel. Perubahan $\mathrm{pH}$ pada muatan variabel akan membuat terjadinya transfer $\mathrm{H}^{+}$dan $\mathrm{OH}^{-}$(White, 1981).

Pelepasan P dari tanah dapat terjadi melalui desorpsi $\mathrm{P}$ dari $\mathrm{P}$ yang disorpsi pada permukaan tanah, tapi juga melalui pelarutan mineral $\mathrm{P}$ dan mineralisasi $\mathrm{P}$ organik. Seperti terjadinya sorpsi, desorpsi juga terjadi melalui pertukaran ligan dengan $\mathrm{OH}^{-}$. Namun, desorpsi $\mathrm{P}$ dari permukaan tanah adalah proses yang lambat daripada proses sorpsi. Sorpsi $\mathrm{P}$ adalah kombinasi dari adsorpsi dan presipitasi, artinya beberapa ion $\mathrm{P}$ yang disorpsi oleh tanah tidak begitu saja bisa didesorpsi, terutama jika struktur cincin telah terbentuk. Pengikatan $\mathrm{P}$ dalam struktur oksida dan hidroksida $\mathrm{Fe}$ dan $\mathrm{Al}$ juga mencegah terjadinya desorpsi (Borling, 2003).

Cepat atau lambat reaksi sorpsi dan desorpsi P pada Oxisol dapat dilacak secara kinetik (Barrow, 1978 dalam White, 1981). Adsorpsi P pada permukaan oksida kristalin dapat berlangsung sangat cepat dimana lebih dari $90 \%$ reaksi terjadi dalam 1 detik pada permukaan goetit (Quirk, 1971 dalam White, 1981). Carritt dan Goodgal (1954 dalam White, 1981) menyatakan keseimbangan reaksi terjadi dalam 1 menit dengan menggunakan suspensi terlarut dari sedimen dan ditemukan reaksi yang cepat dalam tanah yaitu pada oksida dan mineral liat, dimana reaksi bisa sempurna dalam 13hari (White dan Beckett 1964; Chen et al, 1973a; Fitter dan Sutton 1975, dalam White et al 1981). Banyak peneliti melakukan percobaan dengan waktu kontak dari 16 jam sampai 6 hari untuk mempelajari kecepatan reaksi adsorpsi, berapa lama reaksi terjadi. Bagaimana karakteristik sorpsi dan desorpsi fosfor (P) pada Oxisol menurut waktu kontak dengan tanah dan takaran $\mathrm{P}$ yang diberikan.

\section{Tujuan Penelitian}

Peneltian ini bertujuan untuk mengidentifikasi kemampuan Oxisol dalam menjerap dan melepaskan Fosfor (sorpsi dan desorpsi P) dari komplek pertukaran, dan melacak perubahan-perubahan yang terjadi terhadap sorpsi dan desorpsi pada rentang waktu kontak tertentu dan menurut tingkatan takaran P tertentu pula.

\section{Manfaat Penelitian}

1. Dengan mengetahui sifat kinetika dari sorpsi dan desorpsi P Oxisol, diharapkan akan dapat memberikan informasi tentang bagaimana mengelola tanahtanah dengan mineral oksida yang kaya sesquioksida $\mathrm{Al}$, Fe, ketika diberikan pupuk P. Karena pemupukan P menjadi masalah utama dalam pengelolaan tanah ini.

2. Diharapkan dari penelitian ini dapat menghasilkan rekomendasi dalam upaya ameliorasi dan teknologi pemupukan $\mathrm{P}$ pada Oxisol.

\section{BAHAN DAN METODA}

\section{Waktu dan Tempat Penelitian}

Penelitian ini telah dilaksanakan di Laboratorium Jurusan Tanah Fakultas Pertanian Unand, dan di Laboratorium Mineralogi Departemen Ilmu Tanah dan Sumber Daya Lahan Faperta IPB dari bulan April sampai Oktober 2007.

\section{Bahan dan Alat}

Penelitian ini dilakukan dengan menggunakan tanah dari Ordo Oxisol dengan famili Haplorthox Tipik, berliat, kaolinitik, isohipertermik yang berasal dari Padang Siantah Kecamatan Luhak, Kab. 50 Kota Propinsi Sumatera Barat. Deskripsi profil dari Oxisol telah dilakukan oleh Desyosopi (1986) dalam Fiantis (1989). Sampel tanah diambil dari horizon atas pada kedalaman $\quad 0-20 \mathrm{~cm}$. Sampel tanah yang digunakan adalah sampel yang lolos ayakan $2 \mathrm{~mm}$ dan sub sample ditimbang setiap satuan percobaan sebanyak 2 gram setiap satuan percobaan. Untuk meneliti sorpsi dan desorpsi $\mathrm{P}$ maka digunakan larutan $\mathrm{P}$ yang 
berasal dari $\mathrm{KH}_{2} \mathrm{PO}_{4}$ yang kemudian digunakan sebagai perlakuan $\mathrm{P}$. Inkubasi dan ekstraksi P dari sampel tanah dilakukan dengan menggunakan tabung sentrifus yang berukuran $50 \mathrm{ml}$. Untuk mengukur besaran sorpsi dan desorpsi $\mathrm{P}$ dipakai spektrofotometer pada panjang gelombang $882 \mathrm{~nm}$. Untuk menganalisis status kesuburan tanah dan besarnya sorpsi dan desorpsi $\mathrm{P}$ digunakan bahan-bahan kimia sesuai dengan metode analisis yang digunakan.

\section{Metode Penelitian}

Penelitian ini dilakukan dengan metode percobaan laboratorium merupakan percobaan waktu inkubasi sampel Oxisol dengan larutan $\mathrm{P}$ pada beberapa takaran $\mathrm{P}$ dalam rentang waktu tertentu. Untuk menyelidiki karakteristik sorpsi dan desorpsi $\mathrm{P}$ pada Oxisol, maka pada tanah ini diberikan berbagai takaran larutan $\mathrm{P}$ dari $\mathrm{KH}_{2} \mathrm{PO}_{4}$ yang dimaksudkan untuk melihat kemampuan Oxisol dalam mensorpsi $\mathrm{P}$ dengan berbagai takaran dari jumlah yang kecil sampai jumlah yang relatif besar, kemudian diinkubasikan dalam berbagai rentang waktu untuk menelusuri waktu reaksi, "time of reaction", atau waktu kontak antara larutan $\mathrm{P}$ dengan tanah terhadap besarnya dan cepat lambatnya sorpsi dan desorpsi P.

\section{Rancangan Penelitian}

Percobaan dilakukan dengan menggunakan Rancangan Faktorial dalam RAL dengan 10 perlakuan waktu inkubasi (0.04 hari (1 jam) , 0.125 hari (3 jam), 0.25 hari (6 jam), 0.375 hari (9 jam), 1 hari, 3 hari, 6 hari, 9 hari, 18 hari dan 36 hari) dan 8 taraf perlakuan larutan $\mathrm{P}(0,20,40,80,100$, 200, 400, $800 \mu \mathrm{g} / \mathrm{gr}$ tanah) masing-masing perlakuan diulang 3 kali.

Data hasil pengamatan dianalisis dengan menggunakan analisis ragam dan jika terdapat beda nyata maka dilakukan uji lanjut wilayah berganda Duncan (DNMRT) pada taraf $5 \%$.

\section{Pelaksanaan Penelitian}

\section{Persiapan sampel tanah}

Pengambilan sampel tanah dilakukan secara komposit pada kedalaman
0- 20 cm, sampel-sampel kemudian dicampur secara merata. Sampel tanah itu selanjutnya dikering anginkan, dan disimpan dalam tempat tertutup rapat. Sampel tanah kemudian dihaluskan agar lebih homogen, dan diayak dengan ayakan berukuran $2 \mathrm{~mm}$. Tanah yang lolos ayakan dipersiapkan sebagai sampel untuk percobaan laboratorium. Sebelum sampel tanah digunakan untuk percobaan laboratorium, dilakukan pengukuran kadar air tanah dengan metode gravimetrik, dan sampel tanah yang digunakan pada percobaan adalah sampel tanah kering angin.

\section{Pemberian Perlakuan}

Sampel tanah kering angin yang telah dipersiapkan ditimbang sebanyak 2 gram untuk setiap satuan percobaan. Kemudian diberi perlakuan yaitu inkubasi dengan larutan $\mathrm{KH}_{2} \mathrm{PO}_{4}$ dengan takaran : (0, 20, 40, 80, 100, 200, 400, $800 \mu \mathrm{g} / \mathrm{gr}$ tanah). Takaran ini didasarkan pada pemberian pupuk $\mathrm{P}$ yang dilakukan pada Oxisol yaitu sampai $150 \mathrm{Kg}_{2} \mathrm{O}_{5} / \mathrm{Ha}$ setara dengan 33 ppm P. Tanah yang telah diberikan berbagai dosis $\mathrm{P}$, diinkubasikan dalam berbagai waktu inkubasi yaitu : 1 jam (0.04 hari), 3 jam (0.125 hari), 6 jam (0.25 hari), 9 jam (0.375 hari), 1 hari, 3 hari, 6 hari, 9 hari, 18 hari, dan 36 hari. Interval waktu inkubasi yang dipakai ini didasarkan waktu kontak pada reaksi cepat dari adsorpsi $\mathrm{P}$ yaitu pada range waktu 6 jam sampai 16 hari (White, 1981).

Perlakuan dipersiapkan dengan membuat 100 ppm larutan P, kemudian dari larutan tersebut diencerkan lagi untuk membuat larutan P (0 ppm, 2 ppm, 4 ppm, 8 ppm, 10 ppm, $20 \mathrm{ppm}, 40 \mathrm{ppm}$, dan 80 ppm). Setara dengan $(0,20,40,80,100$, 200, 400, $800 \mu g$ (mikrogram P). Larutan P yang mengandung konsentrasi $\mathrm{P}$ diatas diberikan pada tanah sebanyak $20 \mathrm{ml}$ (1 : 10), larutan dan tanah dikocok selama 30 menit, lalu diinkubasi sesuai dengan waktu inkubasi. Kemudian dilanjutkan ekstraksi P meliputi ekstraksi $\mathrm{P}$ untuk menetapkan sorpsi $\mathrm{P}$, dilanjutkan lagi penambahan larutan $\mathrm{P}$ sesuai dengan taraf $\mathrm{P}$ diatas untuk menetapkan desorpsi $\mathrm{P}$ dan ditetapkan dengan ekstraksi $\mathrm{P}$ air dan ekstraksi P-Bray. Pengukuran P dilakukan dengan metoda ammonium molibdat biru 
dan diukur dengan spektrofotometer pada panjang gelombang $882 \mathrm{~nm}$. Selisih antara konsentrasi $\mathrm{P}$ yang diberikan pada oxisol dan $\mathrm{P}$ yang ditemukan kembali dalam aliquot $\mathrm{H}_{2} \mathrm{O}$ dan Bray II ditetapkan sebagai jumlah $\mathrm{P}$ yang di-sorpsi. Desorpsi $\mathrm{P}$ dihitung berdasarkan jumlah $\mathrm{P}$ yang dapat diekstrak oleh air dan Bray II.

\section{Pengamatan}

\section{Analisis Sorpsi dan Desorpsi $P$}

Analisis sorpsi dan desorpsi $\mathrm{P}$ dilakukan pada setiap satuan percobaan pada kedua tahap penelitian sesuai dengan perlakuan waktu inkubasi dan takaran larutan $\mathrm{P}$ yang diberikan. Banyaknya $\mathrm{P}$ yang dapat dilepaskan melalui ekstraksi $\mathrm{H}_{2} \mathrm{O}$ (readily available $P$ ) dan ekstraksi Bray II (slowly available $P$ ) ditetapkan sebagai besaran desorpsi P dari tanah. Banyaknya P yang ter-desorpsi diukur dengan menggunakan metoda ammonium molibdat biru. P yang ter-sorpsi adalah $\mathrm{P}$ larutan yang diberikan sebagai perlakuan dan tidak dilepaskan kembali ke larutan tanah ketika diekstrak dengan $\mathrm{H}_{2} \mathrm{O}$. Prosedur penetapan $\mathrm{P}$ dengan metoda ammonium molibdat biru yang digunakan dalam analisis ini dapat dilihat pada Lampiran 2.

\section{Analisis $\mathbf{p H}$ tanah}

Analisis $\mathrm{pH}$ tanah ditetapkan dengan metoda elektrometrik yang menggunakan $\mathrm{pH}$ meter dengan standar $\mathrm{pH} 4$ dan $\mathrm{pH} 7$ dengan perbandingan tanah dan air $(1: 2)$.

3. Analisis KTK tanah, Penetapan Bahan Organik tanah, Analisis Tekstur, Analisis Kadar Air Tanah, Kadar Fe-dd dan Kadar Al-dd.

Analisis KTK tanah dilakukan untuk mengetahui nilai KTK tanah Oxisol dengan metoda $1 \mathrm{~N}$ Ammonium asetat $\mathrm{pH} 7$. Penetapan bahan organik tanah dengan metoda Walkley and Black. Analisis tekstur tanah dilakukan dengan metoda pipet dan analisis kadar air tanah dengan metoda gravimetrik. Penetapan kadar Al-dd dan Fedd dengan metoda $1 \mathrm{~N} \mathrm{KCl} \mathrm{(Tan} \mathrm{2005).}$

\section{Analisis Mineral Tanah}

Analisis mineral tanah Oxisol dilakukan pada awal percobaan, untuk mengetahui secara kualitatif mineral oksida dan hidroksida $\mathrm{Fe}$ dan $\mathrm{Al}$ yang terdapat pada tanah. Analisis ini dilakukan dengan menggunakan DTA (Differential Thermal Analysis) untuk melihat keberadaan mineral Goetit, Gibsit, kaolinit, haloisit dan dengan X-Ray , untuk menentukan kadar $\mathrm{SiO}_{2}$, $\mathrm{Al}_{2} \mathrm{O}_{3}, \mathrm{Fe}_{2} \mathrm{O}_{3}$. Analisis DTA dilakukan di laboratorium mineralogi Departemen Ilmu Tanah dan Sumber Daya Lahan Fakultas Pertanian Institut Pertanian Bogor.

\section{HASIL DAN PEMBAHASAN}

\section{Hasil Analisis Kimia Tanah Awal Oxisol Padang Siantah Kabupaten 50 Kota.}

Pada Tabel 1 dapat dilihat hasil analisis tanah Oxisol dimana, tekstur Oxisol adalah Liat berpasir, pada sebagian Oxisol ada yang mempunyai kandungan pasir yang tinggi sampai $70 \%$ pada lapisan atas tanah $(0-20 \mathrm{~cm})$ seperti pada Oxisol (Hapludox) yang terdapat di Pakuan Ratu hasil penelitian Hairiah, Noordwijk, Giller (2000). Lebih lanjut dijelaskan oleh Hairiah et al (2000) tanah ini mempunyai kandungan liat yang rendah sehingga kapasitas tukar kation dari tanah ini juga rendah.

Kadar bahan organik termasuk kriteria rendah, dijelaskan Pusat Penelitian dan Pengembangan Tanah dan Agroklimat (2004) bahwa kandungan bahan organik lapisan atas Oxisol yang sedikit agak tebal $(12-25 \mathrm{~cm})$ sebagian rendah dan sebagian lagi sangat rendah, tetapi pada lapisan bawah berangsur menurun menjadi sangat rendah sampai rendah. Akibatnya sumbangan muatan negatif dari tanah ini sangat rendah (Hairiah et al, 2000). Nilai $\mathrm{pH}$ tanah termasuk kriteria masam. Hal ini juga dijelaskan oleh Pusat Penelitian dan Pengembangan Tanah dan Agroklimat (2004) bahwa reaksi tanah pada Oxisol bervariasi sebagian pada Hapludox dan Kandiudox sangat masam sampai masam $(\mathrm{pH} 3,9$ - 4,9) dan sebagian lagi pada Eutrudox menunjukkan reaksi masam $(\mathrm{pH}$ 5,1 - 5,5). Selanjutnya, liat pada oxisol dapat bergranulasi dan keras seperti pasir, sehingga pasir menjadi lebih mendominasi pada Oxisol. 
Tabel.1. Hasil analisis kimia tanah awal Oxisol Padang Siantah

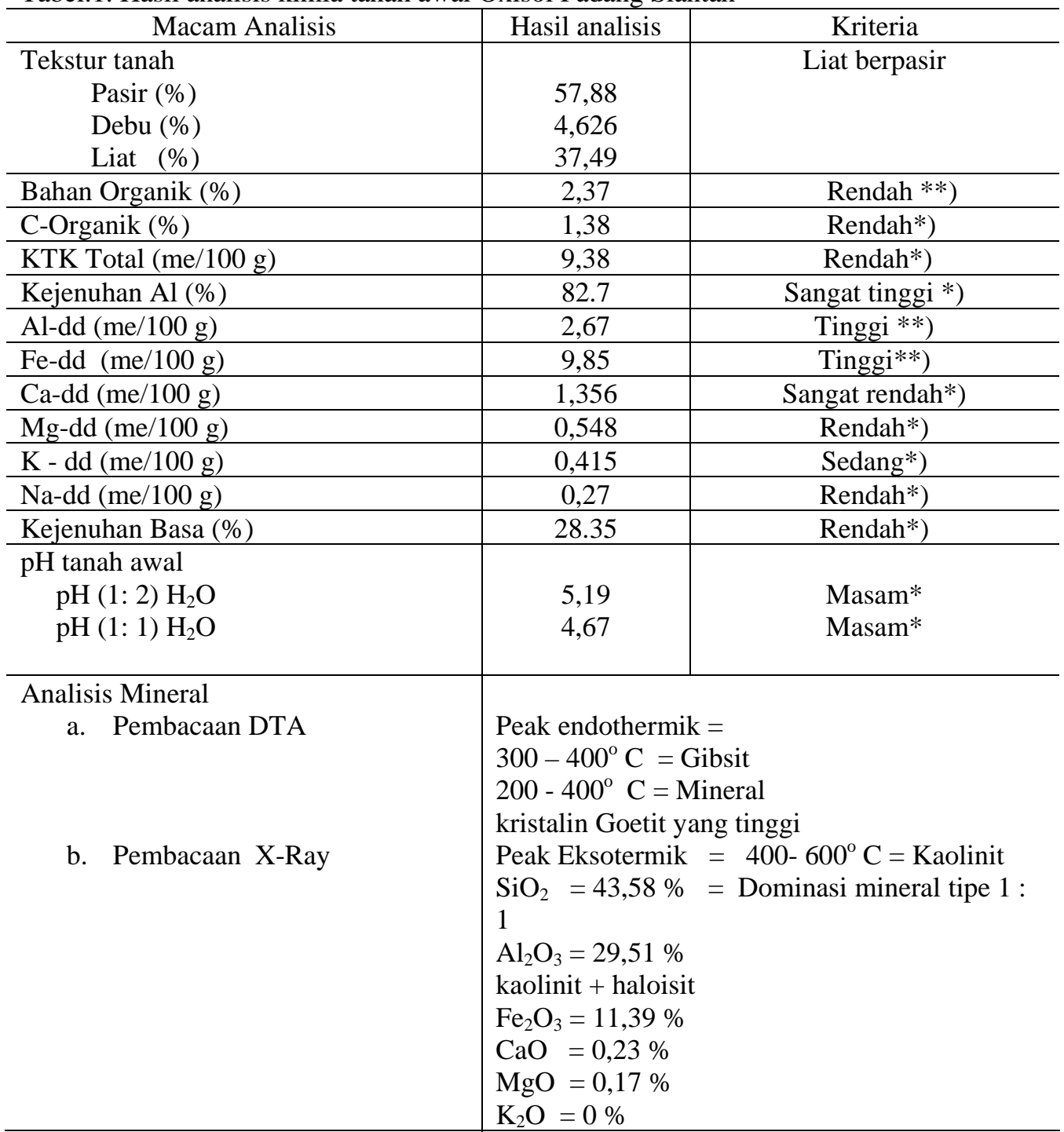

Sumber Kriteria:

*) Tim Pusat Penelitian Tanah dan Agroklimat. 1993. Petunjuk teknis evaluasi lahan. Proyek Pembangunan Penelitian Pertanian Nasional Badan Penelitian dan Pengembangan Pertanian. Departemen Pertanian Bogor.

**) Hakim et al. 1986

Kapasitas tukar kation tanah (KTK) termasuk kriteria sangat rendah, karena kandungan liat yang rendah dan disebabkan dominasi mineral liat tipe $1: 1$, adanya oksida $\mathrm{Fe}$ dan $\mathrm{Al}$ yang mempunyai KTK yang sangat rendah ditambah lagi kandungan bahan organik tanah ini juga rendah (Brady dan Weil, 1999). Sedangkan kejenuhan $\mathrm{Al}$ dan $\mathrm{Fe}$ yang sangat tinggi menunjukkan tanah ini mempunyai kandungan oksida-hidroksida $\mathrm{Al}$ dan $\mathrm{Fe}$ yang relatif tinggi, sebaliknya kandungan mineral dapat lapuk (sebagai cadangan hara) sangat sedikit. Oleh karena proses hancuran iklim yang sangat lanjut, selain kandungan liat yang tinggi, mineral liatnya didominasi mineral liat tipe $1: 1$, khususnya kaolinit, mineral hidroksida-oksihidroksida $\mathrm{Fe}$ (Goetit, hematit) serta Al (Gibsit) dengan KTK yang rendah (Pusat Penelitian dan Pengembangan Tanah dan Agroklimat (2004).

Persentase kejenuhan basa Oxisol sangat rendah karena liat pada Oxisol mempunyai aktivitas yang rendah sehingga tanah ini mempunyai kapasitas yang terbatas 
dalam mengikat kation-kation hara seperti $\mathrm{Ca}^{2+}, \mathrm{Mg}^{+2}$, dan $\mathrm{K}^{+}$, inilah yang menyebabkan Oxisol mempunyai tingkat kesuburan yang rendah dan bereaksi masam (Buckman dan Brady, 1999).

Oxisol mempunyai kapasitas tukar kation (KTK) yang rendah $\left(<16 \mathrm{cmol}^{(+)} / \mathrm{kg}\right.$ liat). Sebagian Oxisol mempunyai KTK efektif (apparent CEC) yang sangat rendah yaitu $<1,5 \mathrm{cmol}^{(+)} / \mathrm{kg}$ liat atau bahkan karena dominasi mineral gibsit $(\mathrm{AlOOH})$ tanah mempunyai muatan netto positif (Pusat penelitian dan pengembangan tanah dan agroklimat, 2004). Oksida dan hidroksida $\mathrm{Al}$ dan Fe yang lebih larut pada Oxisol yang mempunyai reaksi masam akan mengekspos muatan positif yang lebih besar pada permukaan mineral. Adanya muatan positif akan lebih besar kemungkinan untuk ion $\mathrm{P}\left(\mathrm{H}_{2} \mathrm{PO}_{4}{ }^{-}\right)$dan anion lain untuk diikat pada sisi jerapan mineral ini. Ion $\mathrm{P}$ diadsorp pada permukaan oksida $\mathrm{Fe}$ dan $\mathrm{Al}$ melalui interaksinya dengan grup $\mathrm{OH}^{-}$dan $\mathrm{OH}_{2}{ }^{+}$ pada permukaan mineral (Havlin et al, 1999).

Analisis mineral tanah pada Oxisol telah dilakukan dengan DTA, dengan hasil yang dapat dilihat pada Tabel 1, dimana pada peak endotermik yang terletak pada kisaran temperatur $300-400^{\circ} \mathrm{C}$, terdeteksi mineral oksida yaitu Goetit (Limonit), peak endotermal dari Gibsit, yang dicirikan dengan tingginya mineral oksida dari Goetit (Jackson, Lim, Zelazny, 1986). Pada peak Eksoterm, yang terletak pada kisaran 400$600^{\circ} \mathrm{C}$, mineral liat kristalin yang terdeteksi dengan DTA adalah kaolinit, sesuai dengan yang dijelaskan Pusat penelitian dan pengembangan tanah dan agroklimat (2004) bahwa mineral liat yang mendominasi Oxisol adalah tipe 1:1, kaolinit dan vermikulit berlapis antar Al-hidroksida dan mineral hidroksida-oksihidroksida $\mathrm{Fe}$ (goetit, hematit), serta $\mathrm{Al}$ (Gibsit).

Hasil pembacaan mineral dengan $\mathrm{X}$ Ray juga telah dilakukan dan komposisi hasil yang didapatkan dapat dilihat pada Tabel 1, pasir kuarsa lebih mendominasi pada Oxisol Padang Siantah, sehingga mineral liat tipe $1: 1$ seperti kaolinit dan haloisit dengan mempunyai persentase lebih besar yang dominan pada tanah ini. Maka secara umum Oxisol Padang Siantah didominasi oleh oksida Fe, Al dan Si.

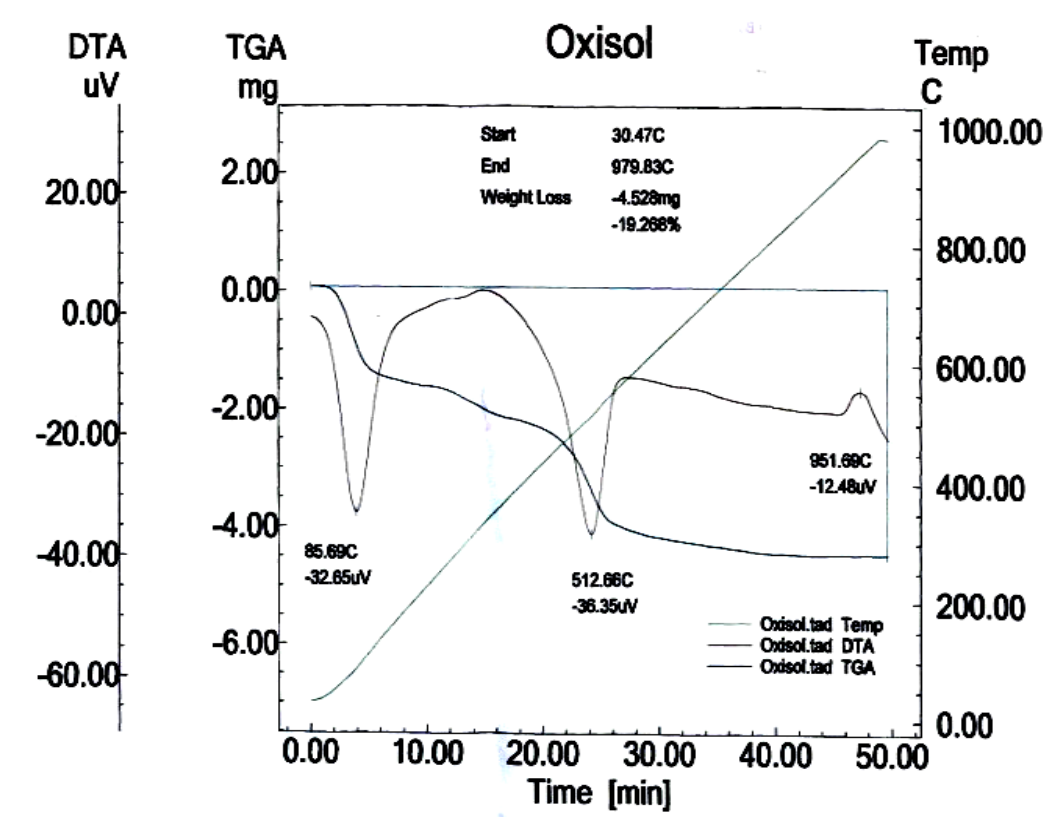

Gambar 1. Hasil Deteksi Mineral Oxisol Padang Siantah dengan DTA (Differenssial Termal Analysis). 


\section{Perbandingan sorpsi P berdasarkan waktu kontak (inkubasi) dan takran P ( $\mu \mathrm{g} / \mathrm{gr}$ tanah) pada Oxisol}

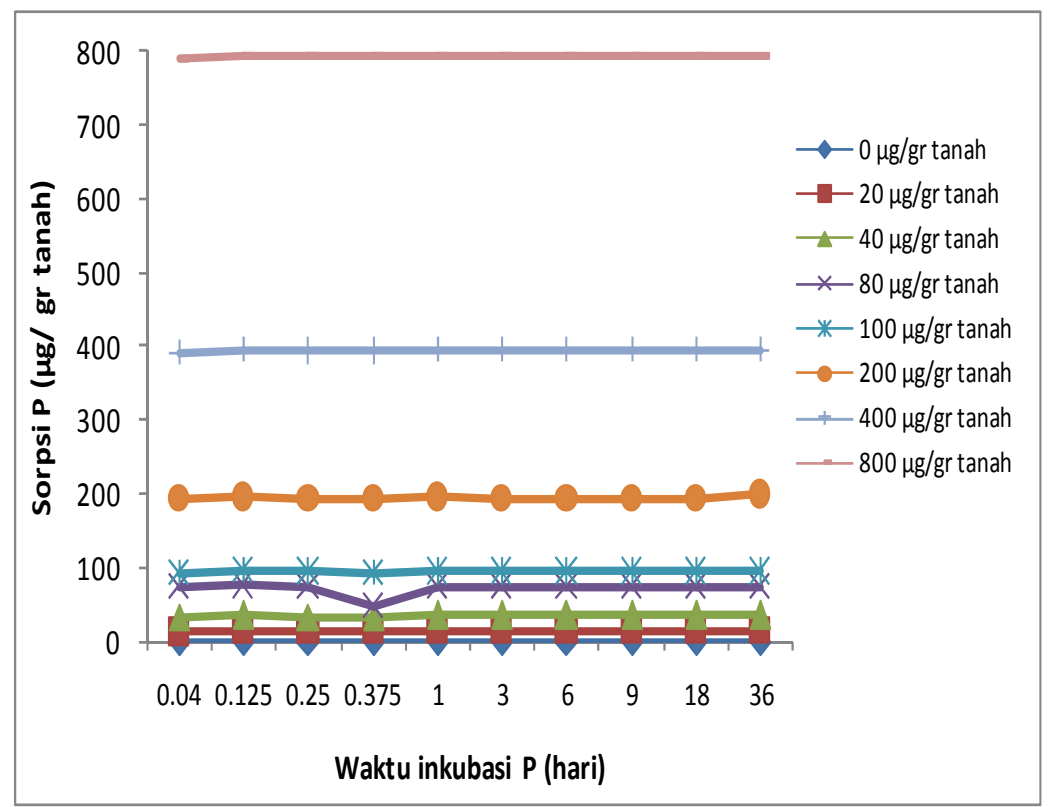

Gambar 2. Perbandingan sorpsi $\mathrm{P}$ berdasarkan waktu kontak $\mathrm{P}$ (hari) dengan berbagai konsentrasi larutan $\mathrm{P}(\mu \mathrm{g})$.

Pada Gambar 2, terlihat kecenderungan jumlah $\mathrm{P}$ yang disorpsi oleh Oxisol pada waktu kontak 0-36 hari pada berbagai konsentrasi larutan $\mathrm{P}$ yang diberikan pada tanah adalah sama. Hampir semua $\mathrm{P}$ yang diberikan melalui larutan $\mathrm{P}$ disorpsi oleh Oxisol Padang Siantah dalam waktu reaksi yang diberikan sampai 36 hari.

Semakin besar konsentrasi larutan $\mathrm{P}$ yang diberikan pada Oxisol maka jumlah sorpsi juga semakin besar, dan dengan bertambahnya waktu inkubasi semakin memperbesar sorpsi P. Dari grafik terlihat semua $\mathrm{P}$ yang diberikan pada Oxisol disorpsi oleh tanah hampir $99 \%$ dari konsentrasi larutan P sampai inkubasi 36 hari dan hanya sedikit sekali $\mathrm{P}$ yang dapat didesorpsi oleh Oxisol.

Larutan $\mathrm{P}$ yang ditambahkan ke tanah biasanya akan dijerap dengan cepat pada awal reaksi, dan konsentrasi $\mathrm{P}$ dalam larutan akan menurun dengan bertambah lamanya waktu kontak. Menurut Fox dan Searle (dalam Ahmad, 1988), proses ini terjadi dalam waktu 1 sampai 7 hari. Yekini et al (dalam Ahmad, 1988), juga melaporkan proses yang cepat pada awal reaksi terjadi dalam beberapa jam pertama kontak antara tanah dan larutan P. Proses sorpsi yang cepat pada awal reaksi dijelaskan oleh Ibrahim dan Pratt (dalam Ahmad, 1988) sebagai reaksi adsorpsi yang sebenarnya terjadi pada permukaan mineral, dimana reaksi lambat disebabkan oleh pemecahan mineral kristalin atau senyawa $P$ amorf.

\section{Pengaruh waktu inkubasi $\mathbf{P}$ dan berbagai konsentrasi larutan $P$ terhadap desorpsi $\mathbf{P}$}

Selanjutnya pada Gambar 4, dapat dilihat desorpsi $\mathrm{P}$ dengan ekstraksi $\mathrm{H}_{2} \mathrm{O}$ dari takaran 0 sampai $800 \mu \mathrm{g} / \mathrm{gr}$ tanah tidak memperlihatkan kecenderungan peningkatan yang berarti. Namun dengan perbedaan waktu kontak $\mathrm{P}$, jumlah $\mathrm{P}$ yang didesorp juga memperlihatkan perbedaan, dimana pada inkubasi 1 jam (0.04 hari) jumlah $\mathrm{P}$ yang didesorp lebih besar daripada waktu inkubasi yang lebih panjang, yaitu 3 jam (0.125 hari), 6 jam (0.25 hari) sampai 9 jam (0.375 hari). 
Hal ini berarti $\mathrm{P}$ yang ditambahkan pada Oxisol akan dilepaskan dalam jumlah yang lebih besar dalam waktu yang lebih singkat, sehingga pemberian pupuk $\mathrm{P}$ pada Oxisol akan lebih baik dilakukan pada saat tanaman benar-benar membutuhkan P untuk pertumbuhannya, ini akan memperkecil kemungkinan terjadinya sorpsi yang lebih besar. Nilai desorpsi $\mathrm{P}$ yang cendrung tidak berbeda sampai takaran $\mathrm{P}$ yang besar dan desorpsi P lebih besar dalam kurun waktu yang lebih singkat pada Oxisol, mengindikasikan $\mathrm{P}$ perlu diberikan dalam jumlah yang tidak terlalu banyak atau sesuai dengan yang dibutuhkan tanaman dan diberikan pada saat tanaman dapat langsung menyerap P. Maka untuk aplikasi pemupukan $\mathrm{P}$ pada Oxisol, perlu diketahui stadia yang tepat dari tanaman dalam menyerap P lebih besar. Oleh karena itu perlu aplikasi pupuk $\mathrm{P}$ secara bertahap sesuai dengan gambaran pertumbuhan tanaman. Tahapan ini dibuat beberapa kali dengan dosis yang tidak banyak (sedikitsedikit) sampai pada masa pertumbuhan vegetatif maksimum dari tanaman, untuk mencegah $\mathrm{P}$ disorpsi lebih banyak pada Oxisol.
Pada Gambar 4, dapat dilihat desorpsi P terjadi lebih besar pada waktu kontak 1 jam (0.04 hari), kemudian menurun drastis pada waktu kontak 0.125 hari(3 jam). Lalu jumlah desorpsi $\mathrm{P}$ meningkat kembali setelah waktu kontak ditambah 0.25 hari (6 jam) sampai 0.375 hari(9 jam). Namun jumlah $\mathrm{P}$ yang dapat didesorpsi tidak sebanyak desorpsi $\mathrm{P}$ pada waktu kontak 1 jam. Terdapat kecenderungan bahwa $\mathrm{P}$ dapat dilepaskan pada waktu kontak tanah dengan $P$ yang lebih singkat. Dengan waktu reaksi yang lebih singkat antara larutan $P$ dan tanah memungkinkan untuk $\mathrm{P}$ tidak langsung dijerap oleh sisi-sisi sorpsi dari Oxisol dan pada Gambar 4 juga terlihat, pertambahan jumlah konsentrasi $\mathrm{P}$ yang diberikan pada tanah pada masa inkubasi 1-9 jam tidak menunjukkan pertambahan jumlah desorpsi P. Dan tidak terdapat konsentrasi $\mathrm{P}$ yang lebih menonjol untuk terjadinya desorpsi $\mathrm{P}$ yang lebih besar. Sampai takaran $800 \mu \mathrm{g} / \mathrm{gr}$ tanah, $\mathrm{P}$ hanya dapat didesorpsi paling banyak 1, 67 \%. Dari jumlah ini sorpsi P hampir mencapai $99 \%$ dari konsentrasi $\mathrm{P}$ yang diberikan. Jadi semakin lama waktu kontak diberikan pada larutan $\mathrm{P}$ untuk bereaksi dengan tanah akan memperbesar sorpsi P.

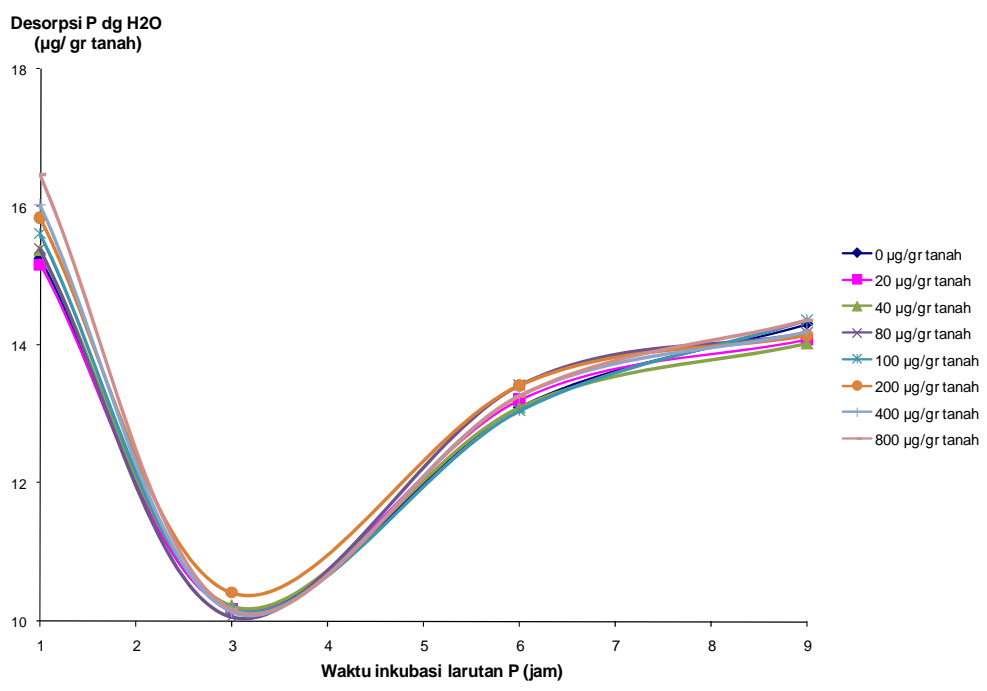

Gambar 4. Pengaruh waktu inkubasi $\mathrm{P}$ (jam) dan takaran $\mathrm{P}$ terhadap desorpsi $\mathrm{P}$ dengan ekstraksi $\mathrm{H}_{2} \mathrm{O}$. 


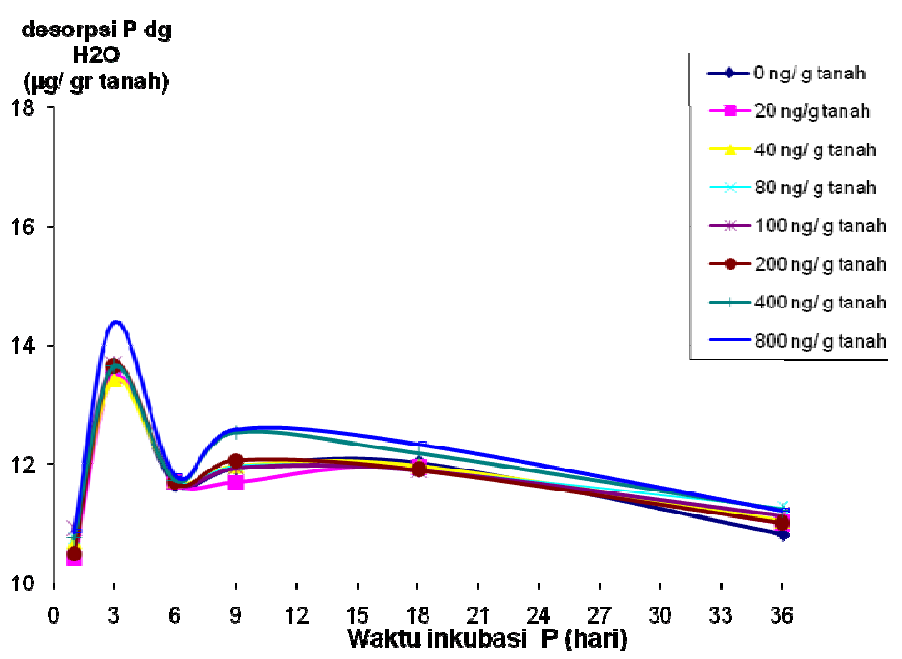

Gambar 5. Pengaruh waktu inkubasi $\mathrm{P}$ (hari) dan takaran $\mathrm{P}$ terhadap desorpsi $\mathrm{P}$ dengan ekstraksi $\mathrm{H}_{2} \mathrm{O}$.

Untuk waktu kontak P yang lebih panjang (hari), terlihat pada Gambar 5, dimana pada waktu kontak 1 hari desorpsi menurun drastis dari waktu kontak 9 jam, dan meningkat drastis pada waktu kontak 3 hari, pada waktu kontak 3 hari ini desorpsi $\mathrm{P}$ mulai terlihat bervariasi menurut konsentrasi $\mathrm{P}$ yang diberikan. Puncak desorpsi terdapat pada konsentrasi P $800 \mu \mathrm{g} /$ gr tanah, namun jumlah desorpsi $\mathrm{P}$ ini masih lebih kecil dari desorpsi $\mathrm{P}$ pada waktu kontak 1 jam pada konsentrasi larutan $\mathrm{P}$ yang lebih rendah. Kemudian terdapat desorpsi $\mathrm{P}$ yang cenderung menurun dengan pertambahan waktu kontak sampai 36 hari. Pada Gambar 5, grafik mulai menunjukkan pelandaian, dimana desorpsi $\mathrm{P}$ terus menurun sampai waktu kontak 36 hari.

Terlihat juga pada waktu kontak P selama 1 hari lebih rendah, namun desorpsi P meningkat kembali setelah waktu kontak P ditambah menjadi 3 hari, tapi jumlah $\mathrm{P}$ yang dilepaskan tidak lebih besar dari waktu kontak $\mathrm{P}$ selama beberapa jam. Jadi $\mathrm{P}$ disorpsi kembali setelah 3 jam sampai waktu 1 hari (sorpsi maksimum) (Gambar 4), dan setelah waktu kontak diperpanjang menjadi 3 hari (Gambar 5) P mulai dilepaskan sedikit demi sedikit ke larutan tanah sampai waktu kontak 36 hari.

Pertambahan waktu kontak P tanpa pemberian bahan humat menyebabkan sorpsi P semakin meningkat, hal ini terjadi karena Oxisol didominasi oleh mineral liat kaolinit, haloisit serta mineral oksida dan hidroksida $\mathrm{Fe}$ dan $\mathrm{Al}$ seperti goetit dan gibsit, yang terlihat pada Tabel 1 . Siradz (2000) menerangkan bahwa kemampuan dari mineral-mineral tersebut dalam mensorpsi $\mathrm{P}$ sangat tinggi, karena adanya penggantian ekspos $\mathrm{OH}$ dari permukaan mineral oleh ion $\mathrm{P}$ dari larutan $\mathrm{P}$ yang ditambahkan pada Oxisol. Mekanisme adsorpsi pada mineral liat dan permukaan sesquioksida adalah dengan ion $\mathrm{P}$ menggantikan grup $\mathrm{OH}$ yang terekspos atau anion lain yang tersorpsi melalui ikatan kovalen, ikatan kovalen koordinat atau ikatan ion antara ion P dan ion Fe (III) dan $\mathrm{Al}(\mathrm{III})$ pada permukaan koloid tanah.

Lebih lanjut Havlin et al (1999), menjelaskan ekspos grup $\mathrm{OH}^{-}$pada patahan mineral dapat mempertukarkan $\mathrm{H}_{2} \mathrm{PO}_{4}$ - sama dengan pertukaran $\mathrm{OH}^{-}$pada permukaan oksida Fe dan Al. Kation-kation yang dapat dipegang pada permukaan mineral liat silikat juga mempengaruhi adsorpsi $\mathrm{P}$ dengan munculnya muatan positif pada permukaan mineral yang dijenuhi anion. Muatan positif yang berjumlah sedikit ini dapat memegang sejumlah anion seperti $\mathrm{H}_{2} \mathrm{PO}_{4}^{-}$. Pelepasan $\mathrm{P}$ yang diadsorp sangat lambat ini, tidak terjadi dalam beberapa jam atau beberapa hari. Besarnya desorpsi menurun dengan waktu. Pada umumnya desorpsi terlihat menjadi sangat lambat setelah kira-kira 2 hari. 
Besarnya desorpsi juga tergantung pada sifat dari kompleks adsorpsi pada permukaan oksida Fe dan Al. Pembentukan struktur 6 cincin atau $\mathrm{P}$ nonlabil akan memperkecil kemungkinan $\mathrm{P}$ dapat didesorpsi, ikatan ion antara ion $\mathrm{P}$ dan oksida $\mathrm{Al}$ akan mencegah terjadinya desorpsi P. Kemungkinan semakin lama diberikan waktu bereaksi antara larutan $\mathrm{P}$ dan tanah akan memperbesar kemungkinan $\mathrm{P}$ akan terikat pada struktur 6 cincin tersebut. Dan semakin memperbesar kemungkinan $\mathrm{P}$ tidak dapat dilepaskan dengan mudah ke larutan tanah. Oleh karena itu semakin memperpanjang waktu inkubasi menjadi tidak efektif untuk memperbesar peluang terjadinya desorpsi yang lebih besar. Dan sebaliknya semakin singkat waktu kontak antara larutan P dan tanah semakin memperbesar terjadinya desorpsi P.

Pada Gambar 6, dapat dilihat desorpsi $\mathrm{P}$ dengan ekstraksi Bray II kecenderungannya hampir sejalan dengan desorpsi $\mathrm{P}$ yang diekstrak dengan $\mathrm{H}_{2} \mathrm{O}$. Pada waktu kontak 1 jam, desorpsi P lebih besar daripada waktu kontak 3-9 jam. Penurunan nilai desorpsi $\mathrm{P}$ terdapat pada waktu kontak 3 jam, kemudian desorpsi $\mathrm{P}$ meningkat sampai waktu kontak 9 jam. Bila dilihat berdasarkan konsentrasi $\mathrm{P}$ yang diberikan pada tanah, desorpsi $\mathrm{P}$ lebih besar pada takaran 80 ppm.

Pelepasan $\mathrm{P}$ maksimum dengan Bray II terdapat pada waktu kontak P 3 hari, dengan takaran P $800 \mu \mathrm{g} /$ gram tanah seperti terlihat pada Gambar 7. Sedangkan untuk waktu kontak P yang lebih panjang sampai 36 hari, jumlah $\mathrm{P}$ yang dapat dilepaskan dengan Bray II, tidak lebih besar daripada $\mathrm{P}$ yang dapat dilepaskan dengan $\mathrm{H}_{2} \mathrm{O}$, dengan waktu kontak yang sama. Pada percobaan waktu inkubasi Oxisol dengan larutan $\mathrm{P}$ dapat dilihat bahwa $\mathrm{P}$ yang larut lebih banyak dilepaskan pada jangka waktu yang relatif pendek (waktu kontak $\mathrm{P} 1$ jam) kemudian disorpsi kembali oleh tanah yaitu pada inkubasi (3 jam-36 hari).

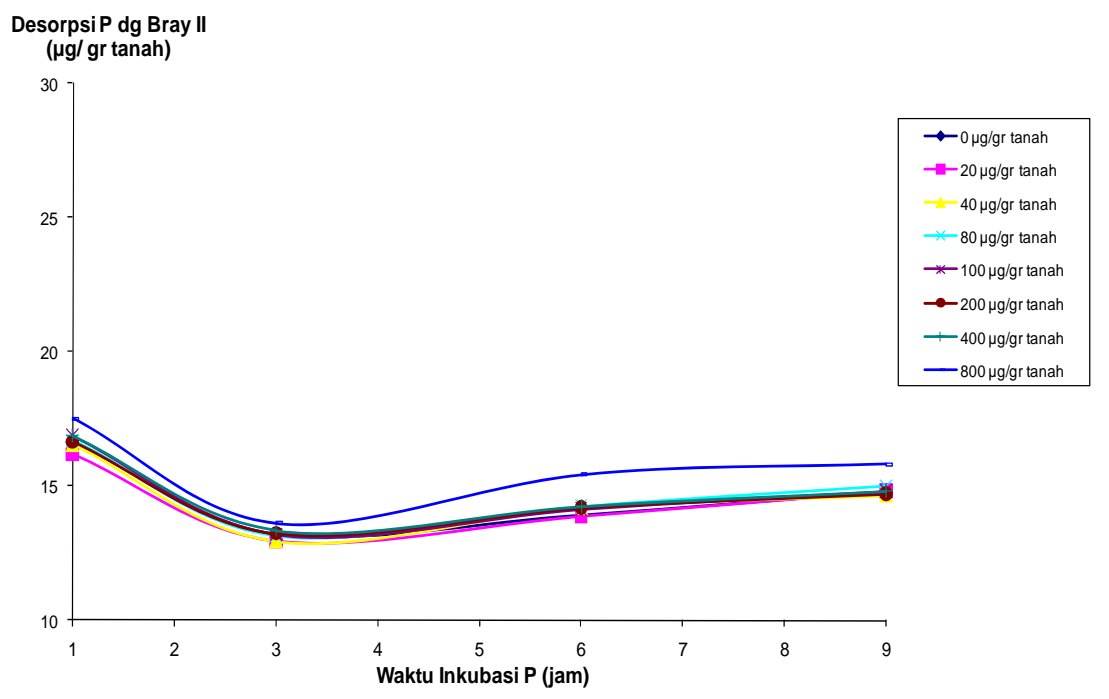

Gambar 6. Pengaruh waktu inkubasi $\mathrm{P}$ (jam) dan takaran $\mathrm{P}$ terhadap desorpsi $\mathrm{P}$ dengan ekstraksi Bray II. 


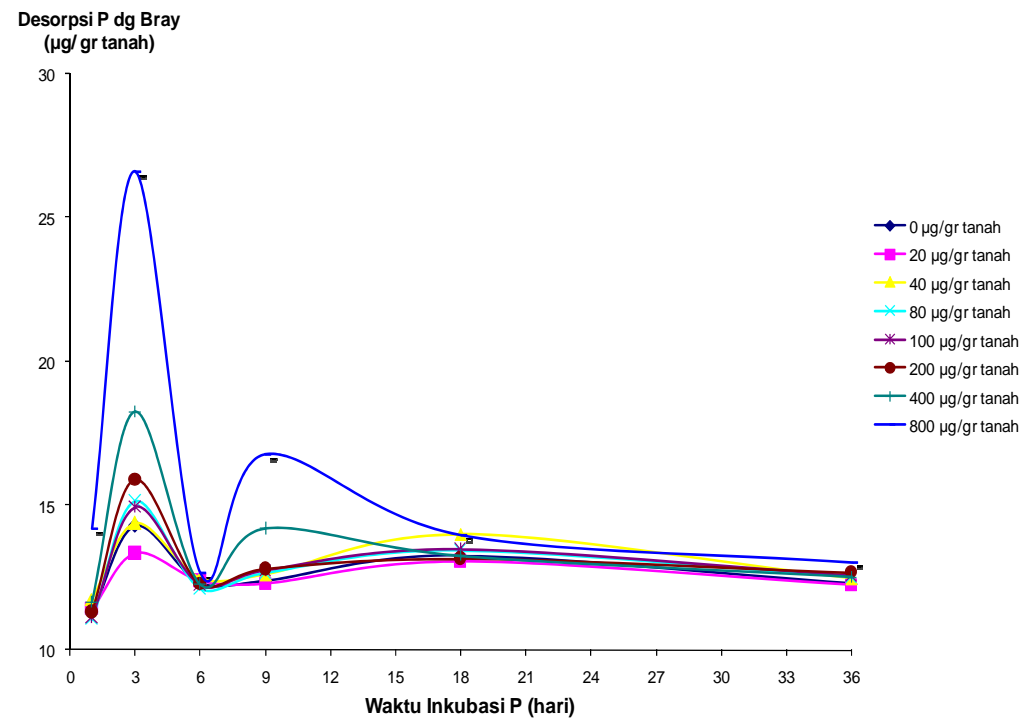

Gambar 7. Pengaruh waktu inkubasi P (hari) dan takaran P terhadap desorpsi P dengan ekstraksi Bray II.

Oxisol yang digunakan untuk produksi tanaman, maka pupuk $\mathrm{P}$ lebih efektif diberikan dengan waktu kontak yang lebih singkat, sehingga pupuk $\mathrm{P}$ tidak diberikan sekaligus dan dalam jumlah yang bertahap karena sampai pemberian takaran $\mathrm{P} 800$ $\mu \mathrm{g} / \mathrm{gr}$ tanah setara $720 \mathrm{Kg}_{2} \mathrm{O}_{5} / \mathrm{Ha}$ desorpsi $\mathrm{P}$ tidak signifikan dibandingkan dengan tanpa pemberian takaran P. Dengan kata lain, dalam aplikasi pemberian pupuk $\mathrm{P}$ pada Oxisol dilakukan tepat pada saat tanaman membutuhkan $\mathrm{P}$ dalam masa pertumbuhannya pada musim tanam tertentu.

Hal ini dilakukan untuk dapat meminimalkan pemberian pupuk $P$, sehingga pemberian pupuk $\mathrm{P}$ yang berlebihan tidak diperlukan pada Oxisol, karena kelebihan pemberian pupuk $\mathrm{P}$ pada Oxisol juga tidak memberikan respon yang baik pada tanaman. Jadi pemberian pupuk P dilakukan pada saat tanaman membutuhkan P lebih optimal bagi pertumbuhannya. Dan tidak membiarkan pupuk $\mathrm{P}$ lama-lama berkontak dengan tanah, karena $\mathrm{P}$ yang diberikan akan berpeluang disorpsi lebih cepat oleh tanah.

\section{KESIMPULAN}

1. Oxisol mempunyai daya sorpsi $\mathrm{P}$ yang sangat tinggi sedangkan desorpsi $\mathrm{P}$ sangat rendah. Oxisol Padang Siantah mampu mensorpsi $\mathrm{P}$ sampai $99 \%$ dari larutan $\mathrm{P}$ yang ditambahkan, dan $\mathrm{P}$ yang dapat dilepaskan maksimal hanya 1,67 $\%$ dari $\mathrm{P}$ yang disorpsi, jadi hanya sedikit sekali $\mathrm{P}$ yang didesorpsi atau dilepaskan.

2. Untuk mencegah sorpsi $\mathrm{P}$ yang tinggi pada Oxisol maka P dapat diberikan bahan amelioran terlebih dahulu ke tanah agar dapat mengurangi sorpsi $\mathrm{P}$ oleh tanah seperti bahan humat. Pupuk $\mathrm{P}$ dapat diberikan pada stadia tanaman dapat menyerap $\mathrm{P}$ dengan maksimum dan secara bertahap (dengan pemberian pupuk $\mathrm{P}$ dalam jumlah sedikit secara bertahap pada masa pertumbuhan tanaman/ plant growth). Agar P dapat dilepaskan lebih banyak ke larutan tanah, sehingga dapat tersedia bagi tanaman.

3. Semakin lama $\mathrm{P}$ dapat berkontak dengan tanah akan memperbesar peluang sorpsi P menjadi lebih besar. Desorpsi P maksimum yaitu pada waktu kontak 3 
hari dengan jumlah desorpsi hanya 1,67 $\%$ dari larutan $\mathrm{P}$ yang disorpsi.

4. Konstituen tanah yang sangat berpengaruh terhadap besarnya sorpsi $\mathrm{P}$ pada Oxisol yaitu dominasi mineral kaolinit, haloisit serta oksida dan hidroksida $\mathrm{Al}$ dan $\mathrm{Fe}$ yang terkandung pada Oxisol Padang Siantah.

\section{Saran}

Pengendalian tingginya sorpsi $\mathrm{P}$ pada Oxisol dapat dilakukan dengan memberikan pupuk $\mathrm{P}$ pada saat yang tepat dimana tanaman dapat menyerap $\mathrm{P}$ dengan maksimum dan perlu penambahan bahan amelioran sebelum dilakukan pemupukan P.

\section{DAFTAR PUSTAKA}

Ahmad, F. 1988. Effect of clay minerals and clay humic acid complexes on availability and fixation of phosphates. Dissertation of Doctor. University of Georgia, Athens, Georgia. 221 p.

Brady, N.C., R.R. Weil. 1999. The nature and properties of soils. Twelfth Edition Prentice Hall. Upper Saddle River, New Jersey. 07458, 881 p.

Buehler. S, A. Oberson, I.M. Rao, D.K. Fiersen, E. Frossard. 2002. Sequential phosphorus extraction of a ${ }^{33} \mathrm{P}$ - labeled Oxisol under contrasting agricultural systems. Institute of Plant Sciences, Soil science society America Journal. 66 :868 - 877 (2002).

Fiantis, D. 1989. Pemberian fosfor pada beberapa family tanah Oxisol dan pengaruhnya terhadap pertumbuhan dan produksi kedelai. Skripsi, Fakultas pertanian Universitas Andalas, Padang.

Hairiah, K., M.Noordwijk., K.Giller. 2000. Pengelolaan tanah masam secara biologi. International Centre for Research in Agroforestry. Jakarta.187 hal.

Havlin, J., J.D. Beaton, S.L Tisdale, W.L Nelson. 1999. Soil fertility and fertilizer. An Introduction to Nutrient Management. Sixth Edition. Prentice Hall. Upper Saddle River, New Jersey, $499 \mathrm{p}$.
Herviyanti. 2007. Upaya pengendalian keracunan besi (Fe) dengan asam humat dan pengelolaan air untuk meningkatkan produktifitas tanah sawah bukaan baru. Disertasi Doktor. Pasca Sarjana Universitas Andalas. Padang. 176 hal.

Hyland. C, Q.Ketterings, D.Dewing, K. Stockin, K. Czymmeck, G. Albrecht, L. Geohring. 2005. Phosphorus basicsThe phosphorus cycle. Department of Crop and Soil Science College of Agriculture and Life Science, Cornell University. 2 p.

K. Borling. 2003. Phosphorus sorption, accumulation, and leaching- Effects of longterm inorganic fertilization of cultivated soils. Department of Soil Science Uppasala Doctoral Thesis. Swedish University of Agricultural Sciences Uppasala. ISSN 1401-6249. ISBN 91-576-6466-8. $39 \mathrm{p}$.

Mikkuta, Christian. 2006. Controls of the phosphate sorption and desorption kinetics of organic matter - goethite associations. Dissertation of Doctoral. Berlin University. 160 p.

Nuryanti, Z. 2003. Karakteristik sorpsi P pada tanah bermuatan bervariasi (Andisol, Oxisol, dan Ultisol). Skripsi S1 Fakultas Pertanian, Unand. Padang.

Pusat penelitian dan pengembangan tanah dan agroklimat. 2004. Sumber daya Lahan Indonesia dan pengelolaannya. Badan Penelitian dan Pengembangan Pertanian. Departemen Pertanian. 242 hal.

Sato, Shinjiro. 2003. Phosphorus sorption and desorption in Brazilian UltisolEffects of $\mathrm{pH}$ and organic anions on phosphorus bioavailability. A Dissertation of Doctor of Philosophy. University of Florida. $124 \mathrm{p}$.

Siradz, S.A. 2000. Mineralogy and chemistry of red soils of Indonesia : IV Phosphorus sorption characteristics of soil, kaolin, and iron oxide concentrates. Soil Science, Faculty of Agriculture, Gadjah Mada University, Yogyakarta. 23 p. 2000. Peranan lempung kaolinit dalam retensi $\mathrm{P}$ pada tanah-tanah 
masam. Jurusan Tanah. Faperta UGM. 7 hal.

Tim Pusat Penelitian Tanah dan Agroklimat. 1993. Petunjuk teknis evaluasi lahan. Proyek Pembangunan Penelitian Pertanian Nasional Badan Penelitian dan Pengembangan Pertanian. Departemen Pertanian Bogor.

White, R.E. 1981. Retention and release of phosphate by soil and soil constituents. In Soils and Agriculture. Critical Reports of applied Chemistry Edited by P.B Tinker. p 71- 100.

Yekini, B., J.A.A. Fiskell, V.E. Berkheiser dan J.I. Street. 1981. Phopsphate adsorbed and desorbed from three regional soils. Soil and Crop Sci. Soc.Florida Proc .40:50-53. 